Check for updates

Cite this: RSC Adv., 2017, 7, 35608

Received 9th May 2017

Accepted 4th July 2017

DOI: 10.1039/c7ra05239a

rsc.li/rsc-advances

\title{
Activation of chrysocolla flotation by organic chelating agents
}

\author{
D. Jiang, (D) ${ }^{a}$ J. Lan, ${ }^{\text {b } W . ~ Z h a o, ~}{ }^{c}$ Z. Zhang ${ }^{d}$ and Y. Lan*e
}

Activation of chrysocolla by organic $\mathrm{Cu}$-chelating agents was studied using flotation tests, instrumental analytical techniques, and computational methods, revealing that the performance of these agents was related to their chemical activity and chrysocolla dissolution properties. The above activation was mainly ascribed to the high chemical activity of organic chelators, which significantly increased collector adsorption capacity.

\section{Introduction}

Although surface hydrophobicity is a necessary condition for mineral flotation, most natural insoluble oxide ores possess strongly hydrophilic surfaces. Consequently, poor surface metal ion diffusion complicates the leaching of these ions into the aqueous phase, hindering the chemical adsorption of conventional collectors on the surface of these minerals and thus leading to unsatisfactory flotation effects.

The development of, and research on, organic chelating collectors has attracted great interest, ${ }^{1}$ because they can form metal chelates on the oxide surface that are more stable than ordinary ionic and covalent metal salts. In addition, organic chelating agents can alter the chemical adsorption capacity of mineral surfaces. ${ }^{2}$ For a long time, chelate collectors have been treated as better selective collectors with seemingly better flotation conventional collectors. ${ }^{3}$

Chrysocolla is a typical insoluble and surface-porous metal oxide mineral containing large amounts of physically and chemically adsorbed water and $\mathrm{OH}-$. So far, the effective flotation-based recovery of chrysocolla is still one of the three major problems of copper oxide flotation. To mitigate this problem, the mineral's surface can be activated by smallmolecule organic chelators that form hydrophobic metal chelates, which enable effective adsorption and strengthening the interaction with the above surface. Herein, we use this representative mineral to study activation by copper-chelating agents and explore the parameters and mechanism of organic chelator-activated insoluble mineral flotation, thereby contributing to the design of novel methods for the same purpose.

${ }^{a}$ School of Materials Science and Engineering, Shanghai University, Shanghai 200072, China

${ }^{b}$ Shanghai Film Academy, Shanghai University, Shanghai 200072, China

${ }^{c}$ Kunming Professional College of Arts, Kunming 650073, China

${ }^{d}$ Yuxi Normal University, 653100, China

'Yunnan University, Kunming 650091, China.E-mail: 1504635629@qq.com

\section{Experimental}

Chrysocolla $\left(\mathrm{CuSiO}_{3} \cdot 2 \mathrm{H}_{2} \mathrm{O}\right)$ ore sourced from the Dongchuan mine and hand-separated from malachite exhibited flotation and test sample purities above 80 and $90 \%$, respectively, with the main impurities being $\mathrm{CaO}$ and $\mathrm{MgO}$. Samples used for flotation tests and adsorption capacity determination exhibited -100 mesh particle sizes, with the Brunauer-Emmett-Teller surface area of the latter samples equaling $132 \mathrm{~m}^{2} \mathrm{~g}^{-1}$. Quartz and calcite showed purities above $98 \%$.

Pentyl xanthate exhibited a purity above 96\%, with other pharmaceuticals being pure or pure for chemical analysis. Distilled water was used in all tests, with pH adjustments performed using $\mathrm{H}_{2} \mathrm{SO}_{4}$ and $\mathrm{NaOH}$.

Single mineral tests were carried out for $1 \mathrm{~g}$ samples in an improved Hallimond single-bubble tube with a flotation volume of $45 \mathrm{~mL}$ and an inflation rate of $60 \mathrm{~mL} \mathrm{~min}{ }^{-1}$. Mixed ore samples ( $1 \mathrm{~g}$ of chrysocolla mixed with $4 \mathrm{~g}$ of calcite or quartz) were separated in a $30 \mathrm{~mL}$-trough flotation machine utilizing a flotation time of $5 \mathrm{~min}$. Adsorption capacities were determined by the residual concentration method at a solid-to-liquid ratio of $1: 45$ using an spw-200 UV-Vis spectrophotometer, and $\xi$ potentials were determined by microscopic electrophoresis. Xray photoelectron spectroscopy (XPS) analyses were performed at the Yunnan University test center with a PHI5500 (PHI, USA) using $\mathrm{Mg} \mathrm{K} \alpha$ ray excitation of $1253.6 \mathrm{eV}$ and X-ray source power of $200 \mathrm{~W}$. The background vacuum was greater than $10^{-7} \mathrm{~Pa}$, while the energy scale was corrected with the binding energy of contaminating carbon C (1s) (284.8 eV).

All calculations were carried out using the Cambridge Serial Total Energy Package (CASTEP) of Material Studio (Accelrys, USA), employing a first-principle pseudopotential method based on the density functional theory (DFT). ${ }^{4}$ The exchange correlation functional used was the generalized gradient approximation (GGA) developed by Perdew, Burke and Ernzerhof (PBE). ${ }^{5}$ DFT calculations employing plane wave (PW) basis sets and ultrasoft pseudopotentials were performed. ${ }^{6,7}$ The 
interactions between valence electrons and ionic cores were represented by ultrasoft pseudopotentials. The kinetic energy cut-off $(310 \mathrm{eV})$ of the PW basis was used throughout the study, and the Brillouin zone was sampled with Monkhorst and Pack special $k$-points of a $4 \times 4 \times 4$ grid for all structure calculations. ${ }^{8}$ For self-consistent electronic minimization, the Pulay Density Mixing method was employed with a convergence tolerance of $2.0 \times 10^{-6} \mathrm{eV}$ per atom. The energy tolerance was $2.0 \times 10^{-5} \mathrm{eV}$ per atom, the force tolerance $0.05 \mathrm{eV}^{-1}$, and the displacement tolerance $0.002 \AA$.

The crystal structure data of chrysocolla obtained from the Crystallography Open Database(http://www.crystallography.net/). ${ }^{9}$

\section{Results and discussion}

\section{Chelator/pentyl xanthate synergistic effect on chrysocolla activation}

Fig. 1 and 2 show the effects of copper-chelating agents on the flotation recovery of chrysocolla and malachite, respectively. The addition of $\alpha$-benzoin oxime, anthranilic acid, and cupferron reagents resulted in maximum flotation recoveries of chrysocolla of 40,63 , and $65 \%$, respectively. For malachite, the addition of alkylhydroxamic acid, $N$-benzoyl- $N$-phenylhydroxylamine, and 8-hydroxyquinoline resulted in maximum flotation recoveries of 72,80 , and $70 \%$, respectively. In addition, these figures reveal that the optimum $\mathrm{pH}$ value corresponded to weakly acidic conditions ( $\mathrm{pH}$ 5-6), which differs from the typically $\mathrm{pH}$ associated with copper ion precipitation and malachite flotation. Thus, the optimum $\mathrm{pH}$ for copper ion precipitation or malachite activation was mainly controlled by chelator chemical activity.

Chrysocolla is a poorly soluble mineral, exhibiting surface properties similar to those of silica or copper oxide in alkaline or acidic media, respectively, e.g., the copper ions on its surface can dissolve at an appropriate $\mathrm{pH}$. At $\mathrm{pH}<5$, dissolved copper(II) ions mainly diffuse into the liquid phase and are not easily adsorbed on the mineral surface; they easily adsorb onto the chrysocolla surface in the form of $\mathrm{CuOH}^{+}$at $\mathrm{pH}$ 5-6, which corresponds to the maximum copper ion concentration on the

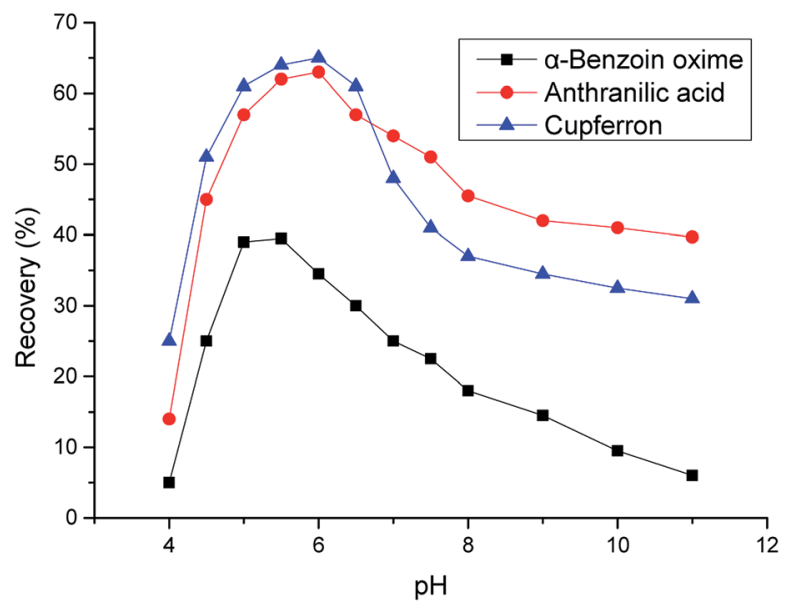

Fig. 1 Effect of chelator and $\mathrm{pH}$ on chrysocolla flotation recovery.

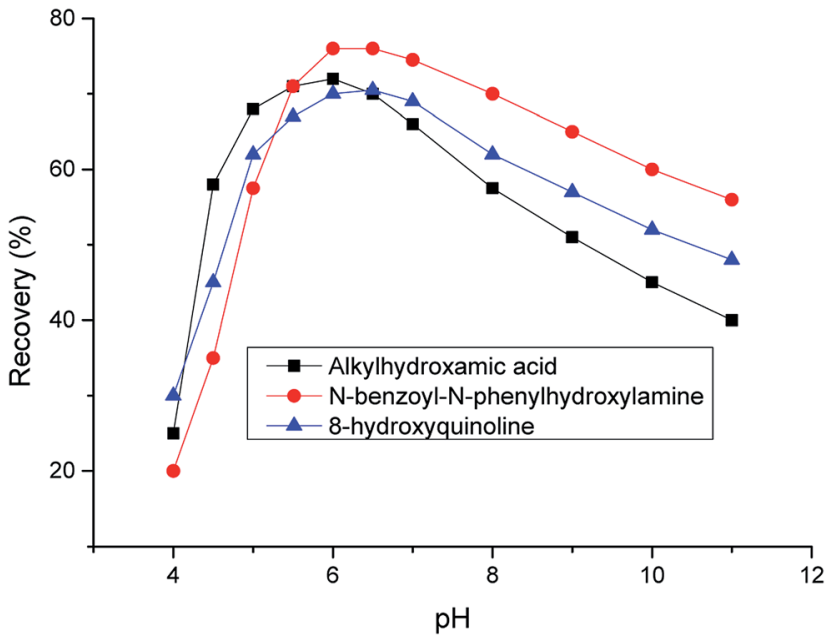

Fig. 2 Effect of chelator and pH on malachite flotation recovery.

surface. The above results show that chrysocolla flotation is controlled by both mineral dissolution characteristics and the chemical activity of chelating agents.

Fig. 3 shows that the use of activators such as $\mathrm{N}$-benzoyl- $\mathrm{N}$ phenylhydroxylamine, 8-hydroxyquinoline, or octylhydroxamic acid results in chrysocolla flotation recoveries of $90 \%$ or more, as compared to values of $<40 \%$ when using the silicon sulfide/ xanthate flotation method.

Fig. 1 to 3 also reveal that chrysocolla activation was enhanced by increasing the activator amount, which can be attributed to the poor solubility and large surface area of this mineral. Thus, a relatively large amount of hydrophobic agent needs to be adsorbed on the chrysocolla surface to increase its hydrophobicity. Pentyl xanthate, on the other hand, exhibits a relatively poor adsorption capacity, requiring a sufficiently high activator concentration to facilitate its adsorption by enhancing the role of surface copper(II) ions and improving the rate of the reaction between the activator and the mineral surface.

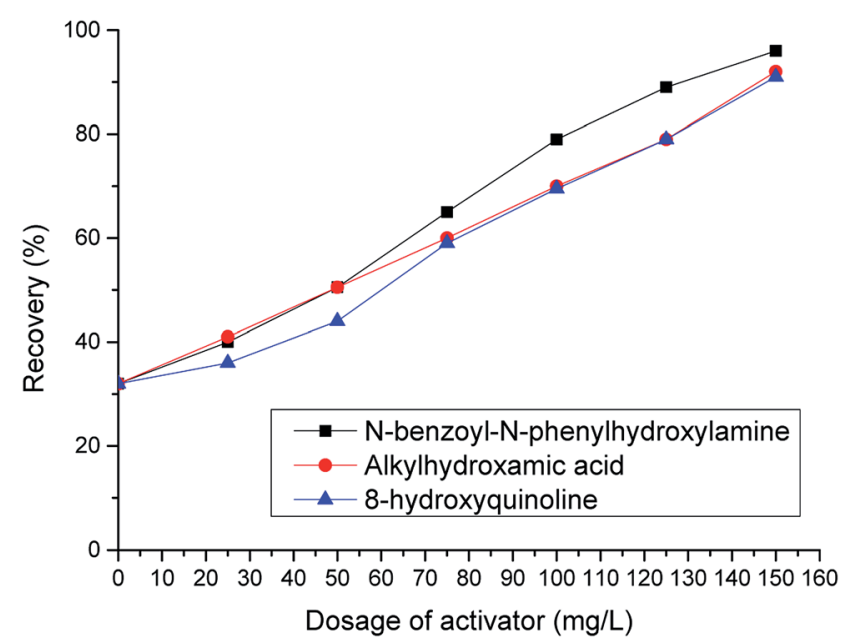

Fig. 3 Activating effect of activator on chrysocolla. 
Table 1 Results of X-ray photoelectron spectroscopy (XPS) analysis of the chrysocolla surface

\begin{tabular}{|c|c|c|c|c|c|}
\hline \multirow[b]{2}{*}{ Sample } & \multicolumn{3}{|c|}{ Binding energy } & \multicolumn{2}{|c|}{ Valence } \\
\hline & $\mathrm{Cu} 2 \mathrm{p}_{3 / 2}$ & $\mathrm{Cu} 2 \mathrm{p}_{1 / 2}$ & Si $2 p$ & $\mathrm{Cu}$ & $\mathrm{Si}$ \\
\hline Chrysocolla/pentyl xanthate & 935.57 & 955.64 & 102.54 & +2 & +4 \\
\hline Chrysocolla/octylhydroxamic acid & 935.79 & 955.69 & 102.53 & +2 & +4 \\
\hline
\end{tabular}

\section{Mechanism of the activation effect}

Although the chrysocolla activation effect depends on the nature of the chelating agent, the activation mechanisms corresponding to the agents should be similar. Herein, octylhydroxamic acid was chosen as a representative chelator to investigate its synergetic effects with pentyl xanthate adsorption on chrysocolla activation.

Photoelectron spectroscopy analysis. Table 1 and Fig. 4 show that exposure to octylhydroxamic acid or xanthate increases the binding energy of copper ions $\left(\mathrm{Cu} 2 \mathrm{p}_{3 / 2}\right)$ on the chrysocolla surface by 1.11 or $0.89 \mathrm{eV}$, respectively, without affecting $\mathrm{Cu}$ valence. Thus, these chelators are involved in chemical interactions with surface copper(II) ions, forming copper(II) octylhydroxamate and copper(II) xanthate adsorbed films, respectively. The obtained results also show that neither of the above chelators interacts with $\mathrm{Si}(\mathrm{Iv})$ on the chrysocolla surface. ${ }^{10}$

Determination of $\xi$-potential and adsorption capacity. Fig. 5 shows that the negative $\xi$-potential of the chrysocolla surface increased in the presence of pentyl xanthate in the $\mathrm{pH}$ 6-8 range, indicating a certain degree of pentyl xanthate adsorption under these conditions. In the case of octylhydroxamic acid, the corresponding increase was most pronounced at $\mathrm{pH}$ 6, which was the optimum pH in Fig. 2. Based on these results, octylhydroxamic acid exhibits a higher adsorption affinity for the chrysocolla surface than pentyl xanthate, activating chrysocolla and controlling its flotation effect. ${ }^{11}$

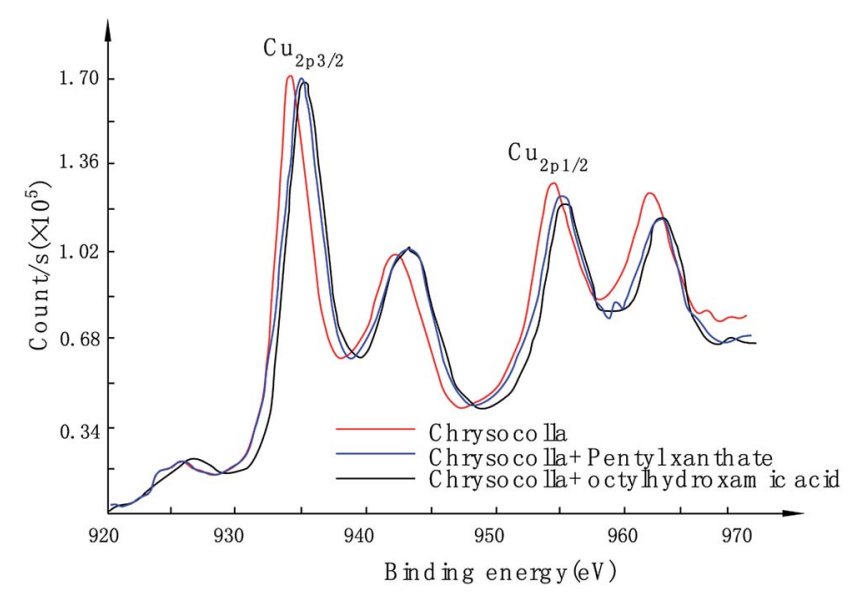

Fig. 4 Cu 2p XPS spectra of chrysocolla samples exposed to various chelators.

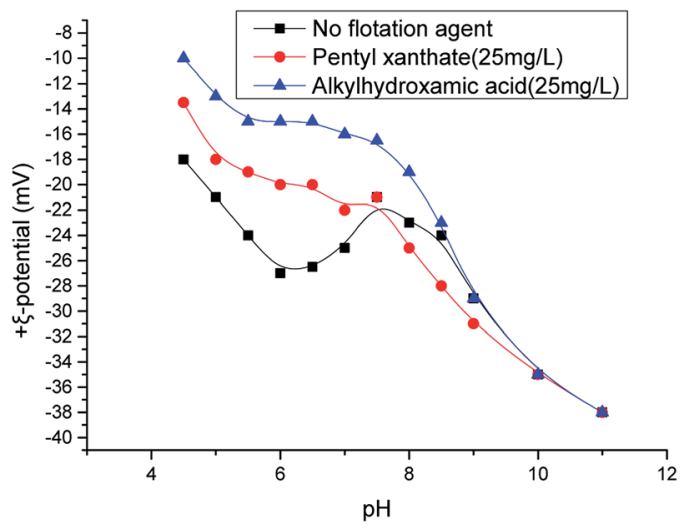

Fig. 5 Effect of activators on the $\xi$-potential of the chrysocolla surface.

Fig. 6 shows that octylhydroxamic acid and pentyl xanthate co-adsorbed onto the chrysocolla surface, with maximum adsorption capacity achieved at $\mathrm{pH}$ 6. This value also corresponds to the optimum $\mathrm{pH}$ of activated flotation, revealing that the adsorption capacity of these agents directly affected the flotation effect. As mentioned above, the concentration of copper ions $\left(\right.$ as $\left.\mathrm{CuOH}^{+}\right)$adsorbed onto the chrysocolla surface is the highest at pH 5-6, and these ions also diffuse very easily to the surface. Under these conditions, the rate and capacity of octylhydroxamic acid adsorption onto the chrysocolla surface are maximized, inducing maximal initial surface hydrophobicity. The thus achieved activation maximizes the pentyl

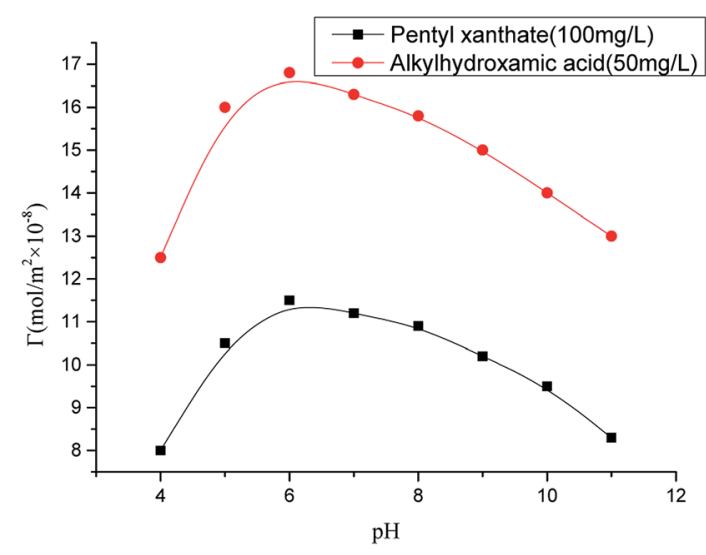

Fig. 6 Effect of pH on chelator adsorption on the chrysocolla surface. 


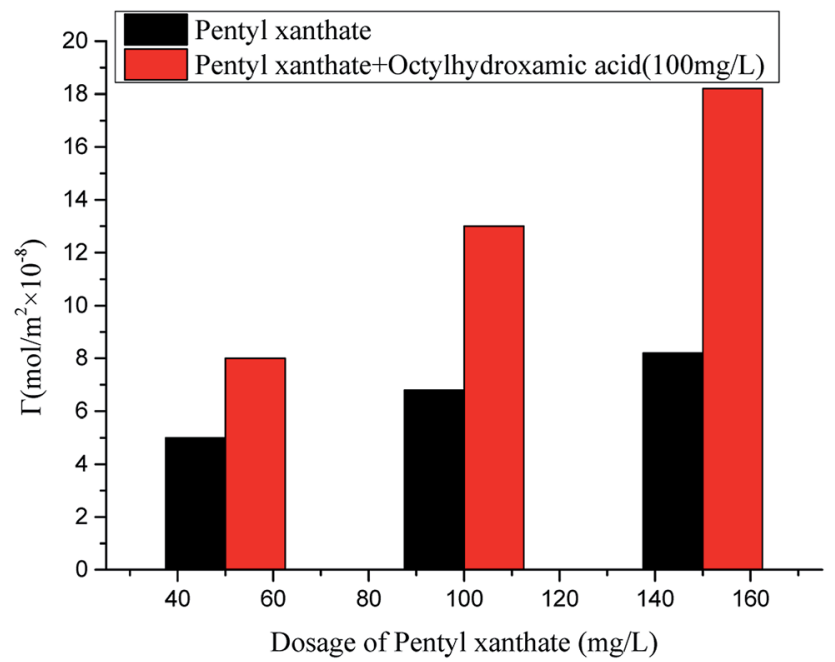

Fig. 7 Adsorption capacity of pentyl xanthate onto the chrysocolla surface.
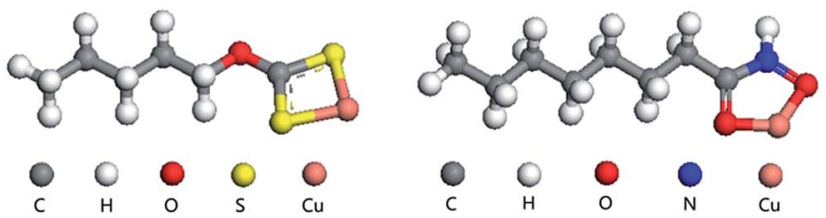

Fig. 8 Model of flotation agent interactions with $\mathrm{Cu}(॥)$.

xanthate adsorption capacity, further demonstrating that mineral surface dissolution characteristics and activator chemical activity control the flotation effect.

Fig. 7 shows that activation by octylhydroxamic acid effectively improved the adsorption capacity of pentyl xanthate and mineral surface hydrophobicity, more than doubling the former parameter at elevated pentyl xanthate levels.

Quantum chemical calculations. The above results and molecular structure considerations indicate that organic chelator binding and the thus-imparted hydrophobicity significantly affect the activation of chrysocolla, which was further investigated by computational methods (Fig. 8).

Table 2 shows that both collectors strongly interact with $\mathrm{Cu}(\mathrm{II})$. Considering population values, the bond between S8 and $\mathrm{Cu}(\mathrm{II})$ is of similar strength to that between $\mathrm{O} 10$ and

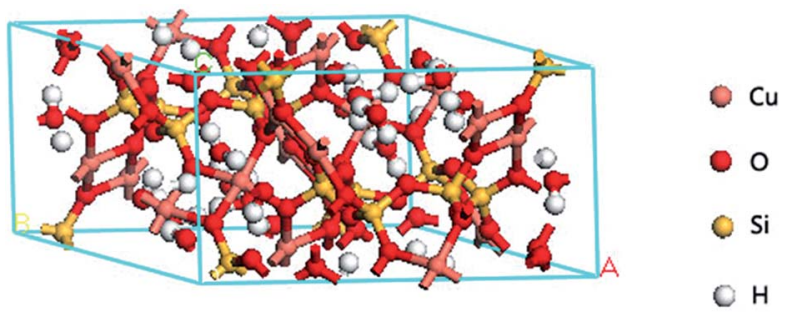

Fig. 9 Molecular model of a chrysocolla unit cell.
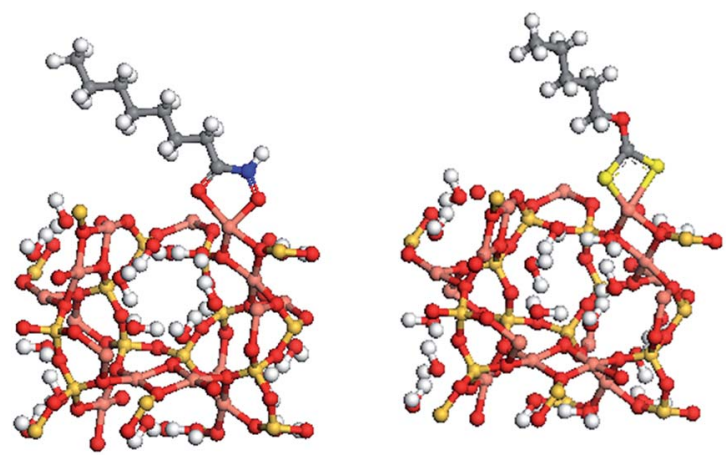

Fig. 10 Interactions of flotation agents with chrysocolla: (left) octylhydroxamic acid and (right) pentyl xanthate.

$\mathrm{Cu}(\mathrm{II})$, while bonding between $\mathrm{S} 9$ and $\mathrm{Cu}(\mathrm{II})$ was stronger than that between $\mathrm{O} 11$ and $\mathrm{Cu}(\mathrm{II})$. However, analysis of the bond length parameters shows that the bond between octylhydroxamic acid and $\mathrm{Cu}$ is shorter (i.e., stronger) than the bond between pentyl xanthate and $\mathrm{Cu}$. The $\mathrm{Cu}$ chelation energy of octylhydroxamic acid $(-30.59 \mathrm{eV})$ was calculated to be greater than that of pentyl xanthate $(-27.33 \mathrm{eV})$, implying that the $\mathrm{O}$, $\mathrm{O}-5 \mathrm{ring}$ chelate formed by octylhydroxamic acid and $\mathrm{Cu}$ is more stable than the corresponding pentyl xanthate chelate, since the ring strain of the former (five-membered ring) is smaller than that of the latter (four-membered ring). Therefore, we can conclude that octylhydroxamic acid is a highly efficient copper collector that is superior to pentyl xanthate (Fig. 9 and 10). ${ }^{12,13}$

The energy of octylhydroxamic acid adsorption on the chrysocolla surface $\left(-56.4 \mathrm{kcal} \mathrm{mol}^{-1}\right)$ was determined to be significantly higher than that of pentyl xanthate $(-33.4 \mathrm{kcal}$ $\mathrm{mol}^{-1}$ ), in agreement with the above results.

Table 2 Population values and chemical bond lengths

\begin{tabular}{|c|c|c|c|c|c|}
\hline \multicolumn{3}{|c|}{ Pentyl xanthate-Cu } & \multicolumn{3}{|c|}{ Octylhydroxamic acid-Cu } \\
\hline Bond type & Population value & Bond length $(\AA)$ & Bond type & Population value & Bond length $(\AA)$ \\
\hline $\mathrm{S} 8-\mathrm{Cu}$ & 0.32 & 2.223 & $\mathrm{O} 10-\mathrm{Cu}$ & 0.31 & 1.911 \\
\hline S9-Cu & 0.27 & 2.248 & $\mathrm{O} 11-\mathrm{Cu}$ & 0.19 & 2.001 \\
\hline \multirow[t]{2}{*}{$\mathrm{C} 7-\mathrm{Cu}$} & -0.38 & 2.469 & N9-Cu & -0.27 & 2.517 \\
\hline & & & $\mathrm{C} 8-\mathrm{Cu}$ & -0.28 & 2.571 \\
\hline
\end{tabular}




\section{Conclusions}

Herein, we demonstrated the ability of $N$-benzoyl- $N$-phenylhydroxylamine, alkylhydroxamic acids, 8-hydroxyquinoline, and other organic chelating agents to effectively activate chrysocolla, achieving flotation recovery rates above $90 \%$ and thus indicating that certain insoluble metal oxides can be activated by choosing organic chelators with appropriate structures and activities.

Flotation tests showed that the above activation was controlled by both the chrysocolla dissolution characteristics and chemical activity of the chelating agent.

X-ray photoelectron spectroscopy, $\xi$-potential tests, and quantum chemical calculations further showed that both octylhydroxamic acid and pentyl xanthate could be adsorbed onto the chrysocolla surface, with the strong chemical adsorption of the former effectively increasing the adsorption capacity of the latter, thereby improving the surface hydrophobicity to achieve chrysocolla activation.

Adsorption capacity tests showed that activation by octylhydroxamic acid effectively improved the adsorption capacity of pentyl xanthate and mineral surface hydrophobicity, almost doubling the former parameter at elevated xanthate levels.

\section{Acknowledgements}

This work was supported by NSFC-YN (UI037603) and the Yunnan Provincial Science and Technology Department (2009cc011).

\section{Notes and references}

1 J. S. Lee, D. R. Nagaraj and J. E. Coe, Miner. Eng., 1998, 11, 929.

2 M. Minakshi, M. I. Barmi and R. T. Jones, Dalton Trans., 2017, 46, 3588.

3 S. N. Tan, A. Jiang, J. J. Liau, et al., Miner. Process., 2009, 93, 194.

4 M. C. Payne, M. P. Teter, D. C. Allan, T. A. Arias and J. D. Joannopoulos, Rev. Mod. Phys., 1992, 64, 1045.

5 J. P. Perdew, K. Burke and M. Ernzerhof, Phys. Rev. Lett., 1996, 77, 3865.

6 J. P. Perdew and Y. Wang, Phys. Rev. B: Condens. Matter Mater. Phys., 1992, 45, 13244.

7 D. Vanderbilt, Phys. Rev., 1990, 41, 7892.

8 H. J. Monkhorst and J. D. Pack, Phys. Rev. B: Condens. Matter Mater. Phys., 2004, 13, 5188.

9 P. H. Ribbe, G. V. Gibbs and M. A. Hamil, Am. Mineral., 1977, 62, 807.

10 L. Bangrul, The Chelating Flotation Agent, Metallurgical Industry Press, Beijing, China, 1992.

11 Z. Guoxi, Physical Chemistry of Surface Active Agent, Peking University Press, Beijing, China, 1984.

12 T. Watcharatharapong, M. M. Sundaram, G. M. Shafiullah, R. D. Aughterson and R. Ahuja, ACS Appl. Mater. Interfaces, 2017, 9, 17977.

13 M. Minakshi, D. Mitchell, R. Jones, F. Alenazey, T. Watcharatharapong, S. Chakraborty and R. Ahuja, Nanoscale, 2016, 8, 111291. 